\title{
O DIREITO À CIDADE ARBORIZADA: A ARBORIZAÇÃO URBANA COMO INDICADOR DA SEGREGAÇÃO SOCIOECONÔMICA EM BELÉM DO PARÁ
}

\author{
THE RIGHT TO AN ARBOREOUS CITY: THE URBAN AFFORESTATION AS AN \\ INDICATOR OF SOCIOECONOMIC SEGREGATION IN BELÉM OF PARÁ
}

\author{
Gabriel Villas Boas de Amorim Lima ${ }^{1}$, Marina Morhy Pereira ${ }^{2}$, Carlos Roberto Ribeiro Junior ${ }^{3}$, \\ Luiz Eduardo Chaves de Azevedo ${ }^{4}$, Ivan Roberto Santos Araújo ${ }^{5}$
}

\begin{abstract}
RESUMO
A constituição de áreas verdes em Belém do Pará sempre esteve associada às dinâmicas socioeconômicas que consolidaram o binômio centro-periferia. Destarte, este estudo relacionou qualitativamente a implantação e manutenção de espaços verdes urbanos aos perfis socioeconômicos da "cidade das mangueiras", investigando se a arborização planejada estaria associada à dinâmica imobiliária de áreas economicamente atrativas. Metodologicamente, utilizou-se uma compilação de pesquisas sobre a arborização urbana juntamente com registros georreferenciados para constatar a dicotomia socioambiental existente. Os resultados indicaram que áreas centrais possuem sistemas arbóreos planejados e de grande porte, demarcando paisagisticamente territórios elitizados. Ademais, identificou-se que o atual desenvolvimento arbóreo é delineado por interesses imobiliários de capitalização do solo urbano, produzindo espaços verdes como instrumentos de valorização e distinção socioeconômica - fenômeno denominado privilégio verde. Nas periferias, a arborização é não planejada, pontual e arbustiva, dificultando a criação de espaços socioambientais adequados, destacando que a ocorrência arbórea disforme desenvolve problemas de saúde pública, lazer e incompatibilidade com as redes de infraestrutura. Assim, concluiu-se que o direito à cidade arborizada, derivação ecológica da teoria de Lefebvre (1991), distancia-se da realidade belenense ao evidenciar o privilégio verde sobreposto às políticas públicas de bem-estar socioambiental, indicando a concepção de um modelo dicotômico de urbanização.
\end{abstract}

Palavras-chave: Cidade das Mangueiras; Espaços Verdes Urbanos; Privilégio Verde; Dicotomia Socioambiental; Valorização Imobiliária.

\begin{abstract}
The formation of green areas in Belém of Pará has always been associated with the socioeconomic dynamics that consolidated the center-periphery binomial. From this, this study qualitatively related the implementation and maintenance of urban green spaces to the city of mango trees socioeconomic profiles, investigating if planned afforestation could be associated with real estate dynamics in economically attractive areas. Methodologically, a compilation of researches on urban afforestation was used along with georeferenced records to verify the existing socioenvironmental dichotomy. The results indicated that central areas have planned and large arboreal systems, delimiting landscaped elitized territories. Therefore, it was identified that the current arboreal development is delineated by urban land capitalization real estate interests, producing green spaces as instruments of valorization and socioeconomic distinction - phenomenon called green privilege. In the peripheries, afforestation is unplanned, punctual and shrubbery, hindering the creation of adequate socioenvironmental spaces, highlighting that the deformed forestation develops public health problems, recreation and infrastructure networks incompatibility. Thus, it was concluded that the right to the arboreous city, ecological derivation of Lefebvre's theory (1991), distances itself from the Belém's reality by emphasizing the green privilege superimposed on good-be socioenvironmental public policies, assigning the conception of a dichotomous urbanization model.
\end{abstract}

Keywords: City of Mango trees; Urban green spaces; Green Privilege; Socio-environmental dichotomy; Real estate valorization.

Recebido em 14.10.2019 e aceito em 13.01.2020

1 Engenheiro Civil. Mestrando em Eng. Civil. Universidade Federal do Pará (UFPA). Belém/PA. Email: gabrielvbal@gmail.com

2 Engenheira Civil. Universidade Federal do Pará (UFPA). Belém/PA. Email: marinamorhyp@gmail.com

3 Eng. Ambiental e Sanitarista. Esp. em Geoprocessamento. Universidade da Amazônia. Belém/PA. Email: car.jr@hotmail.com

4 Engenheiro Ambiental. Mestre em Engenharia Química. Professor substituto, Universidade do Estado do Pará(UEPA). Belém/PA. Email: educhavesazevedo@gmail.com

5 Engenheiro Ambiental. Mestre em Ciências Ambientais. Professor titular, UNAMA. Belém/PA. Email: engivanrsa@yahoo.com.br 


\section{INTRODUÇÂO}

Um processo intrínseco ao desenvolvimento de cidades brasileiras é a segregação socioeconômica e espacial, repercutindo diretamente no modo de vivenciar a urbe. Dessa forma, a qualidade de experimentação do espaço urbano pode ser associada ao estrato socioeconômico no qual o indivíduo está inserido, usufruindo de seus direitos fundamentais enquanto habitante da cidade, ou, ser invisibilizado pela omissão de políticas públicas consistentes (FONTES, 2018). Com isso, o direito à cidade (LEFEBVRE, 1991) cede-se à filosofia de que o espaço urbano é moldado por condições socioeconômicas discrepantes, emoldurado em indicadores que podem destacar a desigualdade territorial - sendo um deles a arborização (JUSTINO et al, 2019).

Nesse contexto, analisou-se como estudo de caso a arborização da cidade de Belém do Pará, devido a relação peculiar da população com os indivíduos arbóreos presentes nos espaços públicos, majoritariamente mangueiras (Mangifera indica L.), denominando-a como "Cidade das Mangueiras". A partir disso, investigaram-se as possíveis relações da ocorrência de arborização urbana como um elemento que indicasse na paisagem a segregação socioeconômica da cidade.

Sob essa perspectiva, este estudo buscou compreender a hipótese de que a arborização não é pensada como um elemento urbano que proporciona qualidade ambiental a todos os cidadãos de forma satisfatória, mas sim fruto de interesses que divergem dos preceitos defendidos por Lefebvre (1991). Para desenvolver tal análise, explorou-se o papel da arborização na estruturação urbana, de modo a detalhar e analisar seus impactos na paisagem, ressignificando as relações e os benefícios oriundos de uma relação harmoniosa entre Cidade-Homem-Ambiente, o que, neste estudo, denomina-se direito à cidade arborizada.

\section{MATERIAL E MÉTODOS}

A natureza da pesquisa possui um aspecto aplicado a um campo interdisciplinar entre as ciências sociais (urbanismo, sociologia, antropologia, ciência política, direito, economia) e ambientais (ecologia, educação ambiental, saneamento). Quanto aos objetivos, a pesquisa se delimitou a aspectos exploratórios, com procedimentos de investigação bibliográfica e documental que possam embasar a análise do espaço socioambiental concebido (Figura 1).

Dessa forma, a pesquisa bibliográfica procurou ressaltar as impressões registradas na literatura acerca do comportamento da arborização em Belém e de sua possível relação com as condições socioeconômicas da cidade, ainda que registradas de maneira implícita. Já na 
pesquisa documental, foram utilizadas ferramentas como bancos de dados do Instituto Brasileiro de Geografia e Estatística (IBGE — Limites Municipais e Base de Logradouros, 2010) e do Serviço Geológico dos Estados Unidos (USGS) para espacializar condições de arborização em algumas parcelas da cidade. Isso foi realizado através do software de geoprocessamento QGIS, versão 2.18.14. Ademais, o comportamento da malha arbórea da cidade pôde ainda ser analisado por registros fotográficos do Google Street View @ .
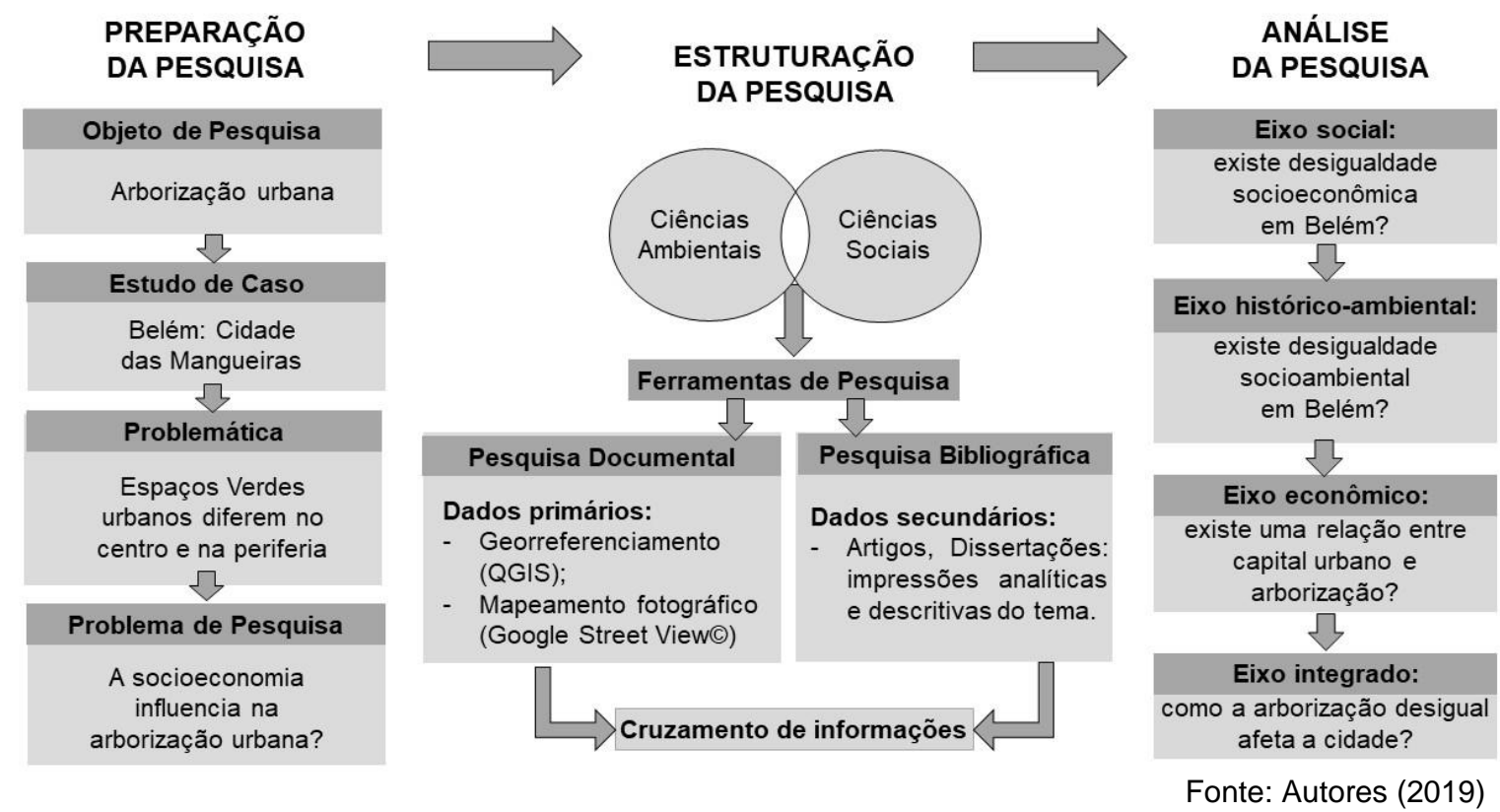

Figura 1. Etapas da Pesquisa.

Figure 1. Research Steps.

Para conceituação, as áreas verdes urbanas tratadas neste estudo correspondem a todos os sistemas arbóreos constituintes do tecido urbano, como praças, parques e bosques além da própria arborização viária. Desse modo, as áreas verdes abordadas podem ser constituídas e gerenciadas por entidades públicas e/ou privadas, implantadas por ações da administração pública ou pelo capital imobiliário local.

\section{RESULTADOS E DISCUSSÃO}

\section{O direito à cidade e a segregação da urbe paraense}

Segundo Lefebvre (1991), o ambiente urbano pós-industrial constitui-se de rearranjos cada vez mais efêmeros, condicionando urbanistas a identificarem padrões de comportamento complexos quanto à relação Homem-espaço habitável. Assim, a constante mutabilidade da práxis social adapta o desenho territorial, imprimindo no espaço físico as contradições sociais estabelecidas. Com isso, áreas adjacentes podem apresentar diferenças expressivas de 
qualificação urbanística em razão do perfil socioeconômico preponderante, resultando em experimentações distintas de qualidade de vida urbana.

Em relação a isso, Harvey (2014) explica que o direito à cidade se expressa na possibilidade de renovação dos interesses particulares do indivíduo, possuindo oportunidades reais de exercer suas funções enquanto cidadão. Desse modo, o habitante da urbe, enquanto portador da necessidade de vivência, busca conciliar constantemente as transformações e os reordenamentos espaciais à manutenção de seus benefícios pessoais, oriundos de seu padrão socioeconômico.

Neste ínterim, Harvey (2014) ainda defende que os cidadãos possuem o direito inato de refazer a cidade individualmente; o que, na prática, configura-se como a transposição da esfera política quanto à tomada de decisão dos posicionamentos coletivos. Isto posto, apontase que as políticas públicas acabam deliberando arranjos suscetíveis à adoção de medidas que podem beneficiar camadas sociais mais influentes do ponto de vista econômico.

Assim, o espaço tende a se reconfigurar em função de um grupo seleto da sociedade, atendendo aos seus padrões de consumo, de ocupação e de utilização das áreas públicas, incluindo as de interesse ambiental (VENTURA NETO; CARDOSO, 2013). Diante disso, Harvey (2014) destaca que o direito à cidade, para ser efetivado, deve ser exercido sem o uso de mecanismos escusos aos princípios universais da igualdade, dos direitos humanos e da liberdade individual.

É com base nesse paradigma que o espaço urbano belenense é polarizado em duas realidades: a central, marcada pelo acesso às conveniências e redes de infraestrutura e serviços; E a periférica, com recursos precários e hipossuficientes. Nesse cenário, é importante ponderar que a polarização centro-periferia não se limita apenas a aspectos geográficos, sendo influenciada por características espaciais (relevo, hidrografia) e sociais (renda, instrução, segurança). Desse modo, espaços polarizados podem coexistir de maneira contígua, reproduzindo realidades contrárias de desenvolvimento em curtas distâncias territoriais. Em Belém, a dicotomia socioeconômica é latente, onde regiões nobres encontram-se fronteiriças a bairros de aglomeração subnormal (VIEIRA; RODRIGUES; RODRIGUES, 2018).

Historicamente, o uso do solo na capital paraense é marcado pelas diferenças de cotas altimétricas, fator que retrata a morfologia da cidade. Dessa forma, as áreas mais altas do relevo urbano foram ocupadas pelas camadas sociais de maior poder econômico, pois assim estariam menos suscetíveis a enchentes e alagamentos (MOREIRA, 1966). Assim, cabia à população de baixa renda a ocupação das áreas de várzea, denominadas regionalmente de "baixadas" (SOARES; CARVALHO, 2018).

A partir disso, a região central da Primeira Légua Patrimonial foi majoritariamente ocupada pela camada socioeconômica superior em assentamentos urbanos planejados, cujo 
traçado retilíneo das glebas permitiu uma organização geométrica da paisagem, como os bairros de Nazaré, Batista Campos e Campina (MOREIRA, 1966). Não obstante, as áreas das baixadas - que correspondem a grandes extensões dos bairros do Guamá, Jurunas e Terra Firme - concentram a maioria dos aglomerados subnormais da cidade, evidenciando a influência da geografia física na geografia urbana desigual (GUSMÃO; SOARES, 2018).

Em relação às áreas verdes, houve redução de cobertura vegetal em todo o território, sendo mais expressiva nas regiões de aglomeração subnormal, em função da ocupação desordenada do espaço (RODRIGUES; LUZ; SARAIVA, 2014). Sobre esse aspecto, é possível inferir que a constituição de áreas verdes urbanas pode estar associada à disposição socioeconômica do espaço. Tal hipótese adquire relevância ao identificar que enquanto a maioria das áreas centrais de Belém possuem um sistema de arborização planejado, com espécies de médio a grande porte, as regiões de baixada evidenciam indivíduos arbóreos de aspecto arbustivo com ocorrência pontual e espontânea.

Todavia, é importante ressaltar que a presença de arborização por si só não define uma condição de igualdade social, ou de exclusão. Por esse motivo, entende-se que a configuração socioeconômica do espaço urbano belenense advém de fatores que não se limitam à temática socioambiental tratada neste estudo, mas sim da confluência de razões históricas, políticas e socioculturais que constituíram o estado paraense e a nação brasileira, resultando na atual morfologia urbana.

\section{A arborização das capitais brasileiras e a dialética por trás da cidade das mangueiras}

Inicialmente, o processo de arborização brasileira retoma ao início do século XIX, quando a chegada da família real portuguesa ao Brasil demandou que os centros urbanos adaptassem suas infraestruturas aos aspectos urbanísticos de higiene propagados pelo continente europeu. Assim, cidades como Rio de Janeiro, Recife, Salvador - e Belém começaram a remodelar suas disposições e ocupações do território antropizado, originando os primeiros projetos técnicos de urbanização do país - incluindo os de sistemas arbóreos. Somado a isso, a ideologia higienista europeia influenciou culturalmente a população a associarem a vegetação nativa à ocorrência de doenças tropicais, pensamento ainda difundido de forma expressiva na Amazônia (SILVA; BATISTA; BATISTA, 2018).

Em Belém, a Intendência de Antônio Lemos (1897-1911) encontrou uma cidade rica em biodiversidade de espécies nativas, contudo, aquém dos padrões europeus de urbanização (RODRIGUES; LUZ; SARAIVA, 2014). Dessa forma, a cidade foi reestruturada à luz da Escola Haussmanniana, que reformulou as redes técnicas de transporte, saneamento e paisagismo período este conhecido como Belle Époque. Desse modo, as intervenções realizadas por Lemos, primeiramente nas áreas centrais, foram pioneiras no Brasil, atribuindo à cidade o título 
extraoficial de "Paris n'América", cujo desenvolvimento físico e cultural era um reflexo direto da influência francesa nos padrões socioeconômicos de sua elite local durante o auge do ciclo da borracha (SARGES, 2004).

É importante ponderar que essa reestruturação urbana era possível mediante uma política de concessões de serviços públicos de infraestrutura para grupos da iniciativa privada, associados à intendência municipal e a sócios estrangeiros (SARGES, 2004). Isso viabilizou nas áreas centrais a distribuição de usos e tipologias de acordo com o traçado alinhado, favorecendo a formação de praças e parques urbanos, além da arborização das vias.

Nesse contexto, a paisagem urbana do centro foi remodelada, substituindo plantas nativas por espécies exóticas segundo critérios técnicos e estéticos de especialistas trazidos do velho continente. Sobre esse aspecto, a espécie com implantação mais relevante na cidade foi a mangueira (Mangifera indica L.), devido a sua adaptabilidade expressiva ao ecossistema amazônico, implicando no crescimento rápido e homogêneo de folhas, galhos e raízes, o que facilitaria a rápida transformação e requalificação da paisagem ambiental urbana (AIROZA, 2010). Isso acarreta, segundo Rodrigues, Luz e Saraiva (2014), na melhora do conforto térmico urbano, pois com a inclusão de mangueiras (de copas densas e espraiadas) haveria mais áreas sombreadas nas vias públicas, estimulando o convívio da população em espaços abertos e o estreitamento da relação Homem-Natureza.

Segundo Sarges (2004), a preocupação de Lemos com a estética ambiental da cidade era tão visível que o mesmo tão logo assumiu o governo do município sintetizou normas que transformaram logradouros públicos em "espaços ambientalmente atraentes", elaborando mecanismos impeditivos à ação predatória do homem em relação às áreas verdes urbanas. Isso pode ser explicado por meio do Código de Polícia Municipal (1901), que era constituído de posturas controversas e punições rigorosas aos infratores do patrimônio natural. O texto previa, dentre as diversas proibições, a de descansar em espaços contemplados com arborização (art.

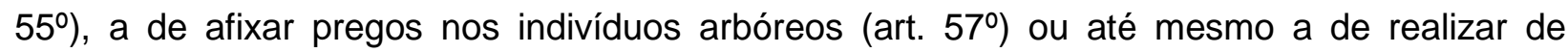
refeições em locais com presença de vegetação sem a autorização prévia da intendência (art. 107) (GAMA NETO, 2013).

Já nas baixadas, que segundo Lemos seriam reestruturadas posteriormente, inexistiam serviços de infraestrutura urbana, servindo como "depósitos de lixo social" (RODRIGUES; LUZ; SARAIVA, 2014). A partir dessa temática, percebe-se que a segregação socioespacial pode ser entendida como uma questão geográfica, o que levou à criação do termo "periferia próxima" (LIMA et al, 2015), que se refere aos bairros de aglomeração subnormal contíguos às áreas centrais elitizadas, fenômeno ainda observado na cidade. Além do mais, é impensável analisar separadamente as segregações socioeconômica e socioespacial, pois ambas refletem o mesmo prisma das desigualdades urbanas, sendo 
oriundos das mesmas variáveis, mas observados por perspectivas econômicas ou territoriais, respectivamente.

Já a partir da década de 1920, com o fim do ciclo da borracha - principal agente impulsionador da economia belenense - a cidade apresentou um considerável declínio econômico, além de expressiva redução populacional. Dessa forma, a insuficiente arrecadação tributária, somada à administração municipal desorganizada, consolidou na cidade, e em especial nas áreas periféricas, sérios problemas referentes à supressão vegetal, sucateamento das redes de saneamento e poluição dos recursos hídricos urbanos, como igarapés (SARGES, 2004). Assim, o plano de sanitização e arborização de todo o território fora interrompido, perdurando uma dicotomia verde no espaço urbano.

Durante a década de 1960, incentivos governamentais de ocupação da Amazônia, através de grandes projetos do setor de minas e energia, reestruturaram o acesso do resto do país à região Norte, simbolizado pela inauguração da BR-010 (Rodovia Belém-Brasília). Na ocasião, a migração de trabalhadores pobres, oriundos de outros estados, intensificou a explosão demográfica das baixadas e das áreas além da Primeira Légua Patrimonial (hoje as regiões das Rodovias BR-316 e Augusto Montenegro), contribuindo para um aumento populacional evidente entre 1960 e 1991 (LIMA et al, 2015). Neste tocante, a rápida e desordenada ocupação dificultou o planejamento municipal de equipar tais áreas de infraestrutura sanitária e arbórea, abrangendo indícios de políticas públicas relacionadas ao assunto apenas no Plano Diretor de 1993, o primeiro do município.

Sob essa ótica, durante as décadas de 2000 e 2010, a relação entre desenvolvimento urbano e arborização municipal pode ter adquirido intuitivamente um caráter imobiliário, onde a ocorrência (e manutenção) dos sistemas arbóreos planejados estariam associadas a uma necessidade escusa de valorizar o território e beneficiar o capital privado. A partir dessa perspectiva, nota-se que a necessidade de geração de renda fundiária diferencial resultou em processos habituais de requalificação ambiental de espaços públicos com finalidades privadas, discussão aprofundada posteriormente.

Apesar dessa crescente valorização de espaços verdes urbanos, um levantamento realizado pelo IBGE (2012), denominado "Características urbanísticas do entorno dos domicílios", evidenciou, dentre outros fatores, que a "Cidade das mangueiras" ocupava o posto de capital estadual menos arborizada do país, com apenas $22,4 \%$ de arborização média nos arredores residenciais. Nesse cenário, Brasil (1994) identificou que bairros centrais - como Nazaré, Batista Campos e Umarizal - registravam a média de 80,31 árvores/km de vias, enquanto o índice para Guamá, Terra Firme e Jurunas (consideradas áreas de baixada) era de apenas 27,58 árvores/km. 
Em termos demográficos, Brasil (1994) ponderou que, de acordo com a base de dados do Censo Demográfico de 1991, 273.471 pessoas habitavam áreas de aglomeração subnormal dentro da primeira légua patrimonial da cidade; o que, na época, era equivalente a $34,5 \%$ da população total do município. No entanto, apenas $5 \%$ da cobertura verde da cidade encontrava-se nessas áreas, enfatizando a premissa de que a arborização era abordada como um elemento urbano de natureza mais econômica do que socioambiental.

De maneira análoga, os estudos de Rodrigues, Luz e Saraiva (2014) e Barros et al. (2017) se dispuseram a verificar o padrão de arborização desigual observado por Brasil (1994) por análises comparativas entre os bairros de Nazaré e Guamá e Cidade Velha e Terra Firme, respectivamente. Desse modo, ambos os estudos concluíram que as zonas centrais possuem condições mais satisfatórias de arborização planejada em relação às áreas subnormais adjacentes, impactando diretamente em melhorias no conforto térmico (BARROS et al, 2017) e nas condições estético-sanitárias (RODRIGUES; LUZ; SARAIVA, 2014).

Quanto à impressão da população acerca da arborização, Silva, Batista e Martini (2014) avaliaram a percepção subjetiva de moradores dos bairros de Nazaré e Guamá a respeito da influência das árvores no cotidiano urbano. No estudo, os moradores do bairro de Nazaré evidenciaram a geração de sombreamento e qualidade de vida associada às áreas verdes, seguida pela beleza oriunda do sistema arbóreo, pela melhora da qualidade do ar e pela preservação faunística urbana. Já no bairro do Guamá, os habitantes priorizaram o sombreamento, a purificação do ar e a possibilidade de preservação da avifauna local.

Em complementação a isso, Rodrigues, Luz e Saraiva (2014) quantificaram a desproporção dicotômica entre a arborização desses dois bairros, evidenciando que ambos estão abaixo do índice de cobertura vegetal mínimo de 30\% recomendado pela Organização das Nações Unidas (ONU) (BORGES; MARIM; RODRIGUES, 2019). Nesse cenário, o bairro de Nazaré apresentou apenas $11,35 \%$ de cobertura vegetal, enquanto o Guamá evidenciou preocupantes 5,42\%. Segundo a ONU, áreas com índice de arborização inferior a 5\% possuem características compatíveis com um deserto florístico. Em relação à densidade populacional, ambas as realidades também divergem do ideal previsto: enquanto Nazaré apresenta $8,39 \mathrm{~m}^{2}$ de cobertura vegetal por habitante, no Guamá tal proporção é de $2,40 \mathrm{~m}^{2} / \mathrm{hab}$, abaixo do recomendado pela ONU $\left(12 \mathrm{~m}^{2} / \mathrm{hab}\right)$.

Desse modo, a diferença arbórea entre bairros é tão nítida que, segundo Silva, Batista e Martini (2014), 70\% da população de Nazaré reconhece como "justo" o título de "Cidade das mangueiras" a Belém, enquanto no Guamá tal reconhecimento mal chega a 30\%. Tal dicotomia permite inferir a ideia de que a população belenense tem conhecimento da maioria dos benefícios associados à arborização e de que os mesmos não são disponíveis de forma 
igualitária, explicitando os privilégios que as desigualdades socioeconômicas geram em uma perspectiva socioambiental urbana.

Acerca desse fenômeno de "vantagem socioambiental" de bairros centrais sobre os periféricos, este estudo busca compreendê-lo sob a nomenclatura de "privilégio verde", que representa o recondicionamento paisagístico-urbano diretamente vinculado a interesses econômicos do setor imobiliário. Nessa conjuntura, o privilégio verde pode englobar desde a concepção dos espaços verdes urbanos até a sua forma de utilização, evidenciando a alteração do perfil socioeconômico de ocupação adjacente dessas áreas após a inserção de infraestrutura paisagística.

Como consequência socioambiental, o privilégio verde propõe que áreas com cobertura vegetal proporcionam melhores condições de bem-estar, lazer e saúde urbana aos moradores do entorno, desde que dotadas de infraestrutura adequada. Da perspectiva socioeconômica, o privilégio verde objetifica a arborização e seus equipamentos como instrumentos de marketing ambiental sob o estigma de aquisição de qualidade de vida por meio da capitalização do espaço natural da cidade. Dessa forma, verifica-se que o privilégio verde está diretamente associado ao que Harvey (2014) denomina de 'urbanização do capital', no qual o planejamento urbano é utilizado para fins de valorização do solo (nesse caso, em especial as áreas verdes), invisibilizando políticas públicas que promovam assistência e dignificação socioambiental.

\section{Privilégio Verde e a produção econômica da arborização}

A partir da investigação do privilégio verde, entende-se que a disposição de áreas verdes urbanas possa ser orientada em função de interesses econômicos do setor imobiliário, associados à falta de efetividade de políticas públicas concernentes ao bem-estar socioambiental da cidade. Sob esse contexto, a intenção de produção incessante do capital resulta na objetificação da arborização como um fator de atratividade socioespacial, gerando espaços comercializáveis de maior valor-agregado, conforme infere os estudos de Del Fiori et al (2018). Associado a isso, ações inábeis do poder público em efetivar seus instrumentos legais de ampliação, reestruturação e consolidação de malhas arbóreas tornam os procedimentos técnicos de requalificação urbano-paisagística mais burocráticos, morosos e ineficazes na melhoria dos espaços verdes.

Nesse prisma econômico, a pressão feita pelo mercado imobiliário nas autoridades políticas pode ser evidenciada como o principal motivo de implantação ou reestruturação de sistemas de arborização urbana em Belém. Isso acontece em razão dos espaços verdes tendem a beneficiar os imóveis indiretamente do ponto de vista estético-paisagístico, gerando núcleos de atratividade socioeconômica. Baseada nessa tendência, a perspectiva da cidade é 
a de requalificar ambientalmente áreas urbanas apenas se nelas existirem interesses em explorar o capital urbano de forma latente, gerando mais fatores atrativos e, consequentemente, maximizando as receitas obtidas de sua objetificação implícita. Caso contrário, áreas que não se encontram no espectro de especulação imobiliária dificilmente apresentarão intervenções adequadas e expressões satisfatórias de qualidade ambiental urbana.

Um exemplo dessa conjuntura é a região da Rodovia Augusto Montenegro, inicialmente ocupada pela população de baixa renda e que, a partir do final da década de 1990, vem sendo reconfigurada urbanisticamente. Nessa área, empreendimentos horizontais de alto padrão foram implantados segundo o anseio da classe média-alta em vivenciar espaços livres de violência ou trânsito característicos dos centros urbanos - fenômeno este análogo aos subúrbios estadunidenses (VENTURA NETO; CARDOSO, 2013; CARDOSO et al, 2016).

Contudo, a discrepância entre as condições de arborização da via se compatibiliza com os diferentes perfis socioeconômicos da região. Enquanto trechos da rodovia onde predominam condomínios de luxo apresentam sistema de arborização planejado (Figura 2-A), regiões de comércio popular e aglomeração subnormal são desprovidas de áreas verdes (Figura 2-B), evidenciando um contraste socioambiental na mesma área urbana. Com isso, o privilégio verde tornou-se um ato privado no espaço público, evidenciado em regiões contíguas (Figura 2-C).

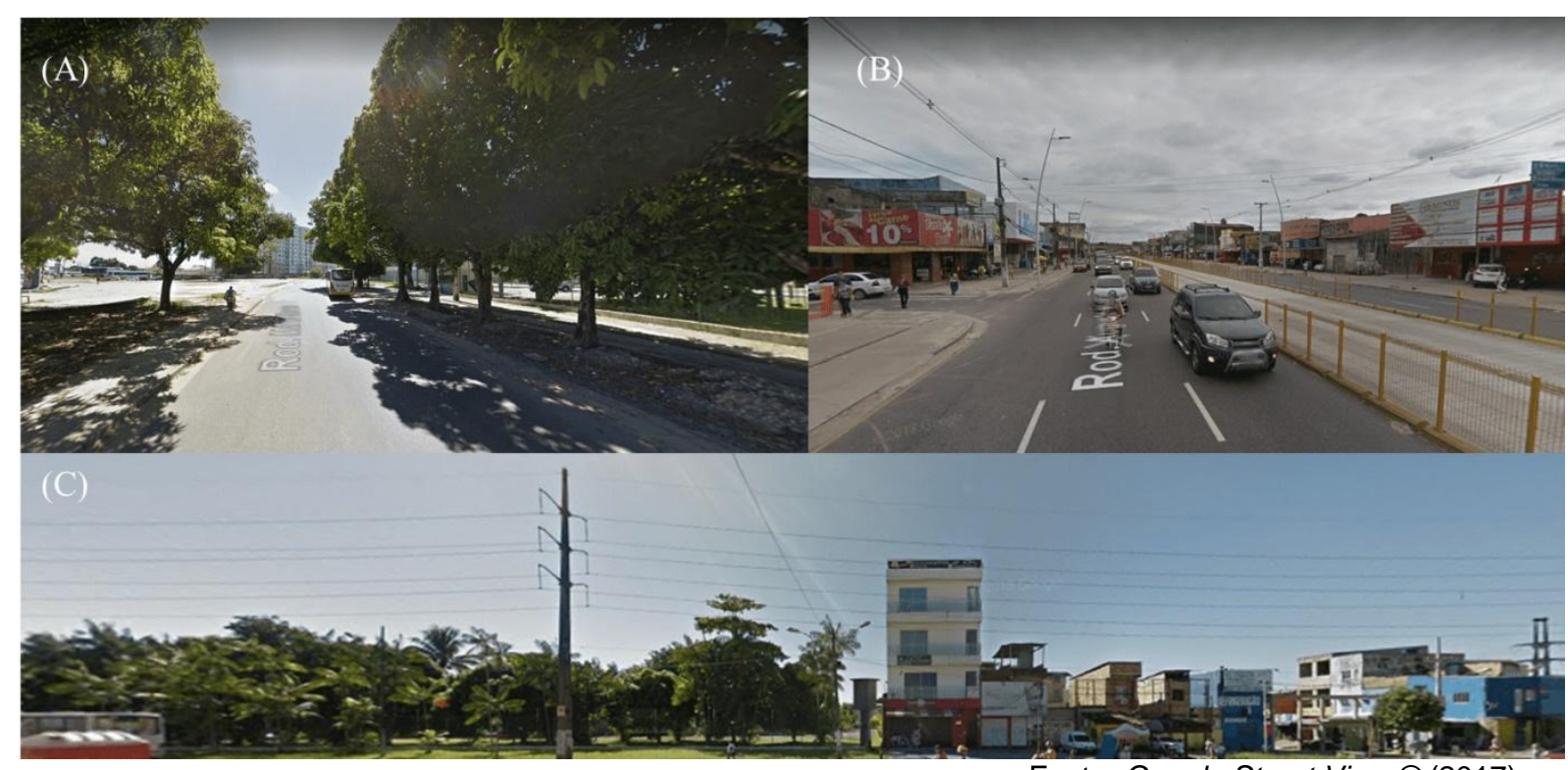

Fonte: Google Street View $\mathcal{C}(2017)$

Figura 2. Contradições socioambientais na Rodovia Augusto Montenegro - regiões de condomínios de luxo (A), de comércio popular (B) e o choque socioambiental (C).

Figure 2. Socio-environmental contradictions on the Augusto Montenegro Highway - regions of luxury condominiums (A), of popular commerce (B) and the socio-environmental shock (C). 


\section{Direito à cidade arborizada: contrastes e consequências}

Arborizar o espaço urbano beneficia o território não apenas do ponto de vista estéticopaisagístico, como também contribui na melhoria do conforto térmico (WANDERLEY et al, 2017) e acústico (OLIVEIRA et al, 2018), além de auxiliar na preservação da avifauna urbana (VIEZZER et al, 2016). Nesse contexto, tais benefícios possuem acesso restringido em função da ocorrência do que se pode denominar oásis urbanos, ou áreas verdes que desfrutam de considerável potencial socioambiental, quase sempre dispostas em regiões de intensa exploração do capital urbano.

$\mathrm{Na}$ região da Primeira Légua Patrimonial, os contrastes socioambientais podem ocorrer tanto em bairros tradicionalmente dicotômicos como em sub-regiões do mesmo bairro. Dessa maneira, observa-se que bairros tradicionalmente centrais apresentam arborização planejada de grande porte, cujas copas proporcionam túneis verdes característicos nas vias urbanas, como na Avenida Nazaré (Figura 3-A). Em regiões subnormais, a vegetação é arbustiva e pontual, como na Avenida José Bonifácio, principal via do Guamá (Figura 3-B).

Ainda, tais diferenciações podem ocorrer dentro no mesmo bairro, em porções territorialmente contíguas, mas economicamente distintas. Um exemplo claro disso pode ser observado no bairro da Pedreira, cuja Avenida Marquês de Herval possui intensa valorização imobiliária, sendo considerada uma via-parque da cidade (Figura 3-C). Não obstante, a Avenida Visconde de Inhaúma (Figura 3-D), distante menos de cem metros da via-parque, apresenta ocupação subnormal com vegetação não planejada e disforme. 


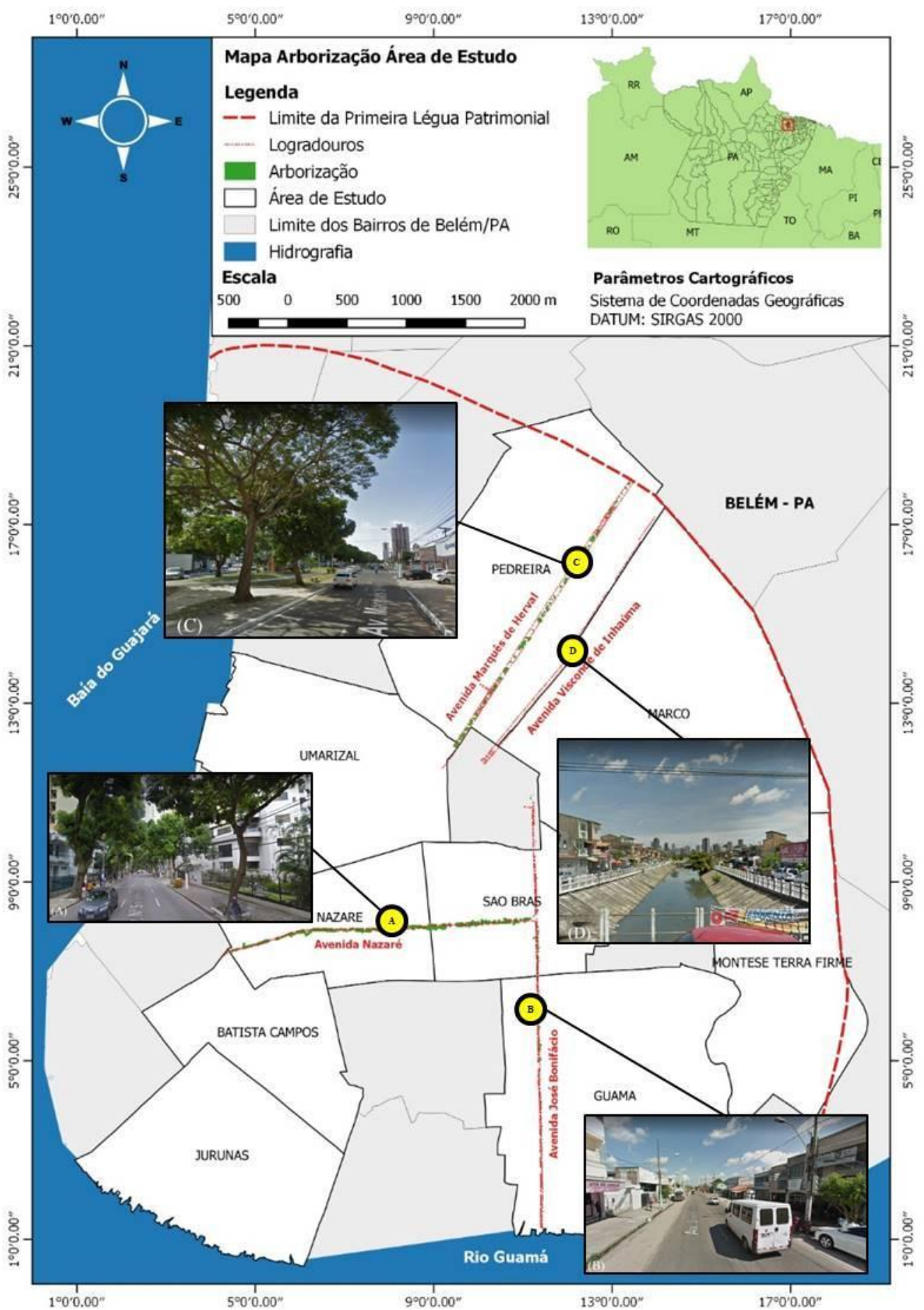

Fonte: Autores (2019)

Figura 3. Contradições socioambientais na Primeira Légua Patrimonial de Belém: Avenidas Nazaré (A), José Bonifácio (B), Marquês de Herval (C) e Visconde de Inhaúma (D).

Figure 3. Socio-environmental contradictions in the First Patrimonial League: Nazaré $(A)$, José Bonifácio (B), Marquês de Herval (C) and Visconde de Inhaúma Avenues (D).

Em relação a isso, analisa-se que as áreas verdes urbanas apresentam traços do perfil socioeconômico da região de situação. Exemplos dessa diferenciação na relação Homem-Natureza urbana são as características de praças centrais e periféricas. Em áreas de 
valorização econômica, a arborização e o paisagismo de bairros centrais são planejados e passam por constante manutenção, como a Praça Batista Campos (Figura 4-A). Já em áreas não valorizadas pelo capital urbano, os espaços verdes apresentam ausência de manutenção e carência de implantação de arborização de médio e grande porte, fatores que desencorajam o desenvolvimento de relações socioambientais em bairros periféricos, como a Praça Princesa Isabel, no Guamá (Figura 4-B).

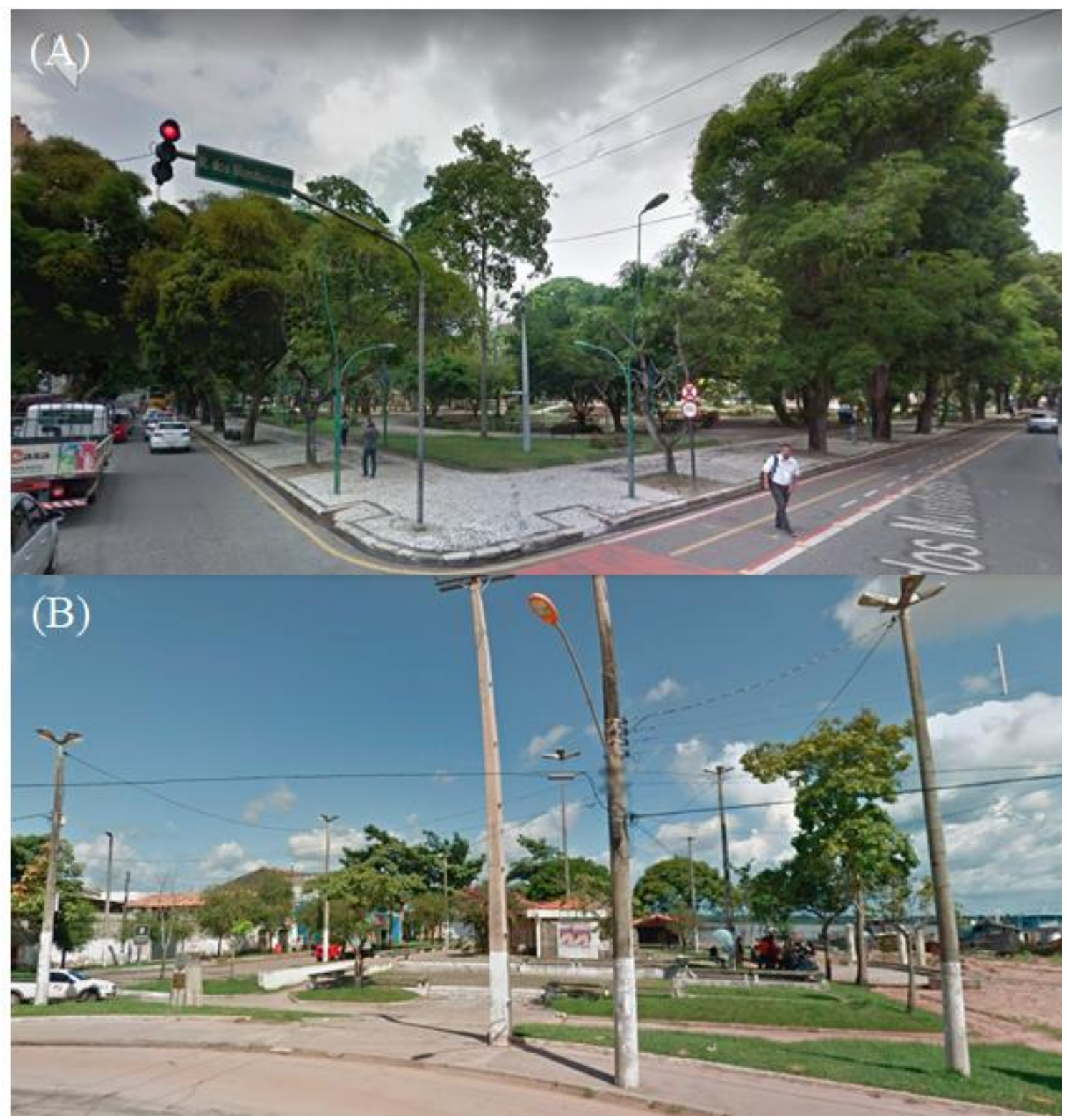

Fonte: Google Street ViewC (2017)

Figura 4. Praças Urbanas em áreas centrais $(A)$ e periféricas $(B)$.

Figure 4. Urban Squares in central (A) and peripheral areas (B).

Como se observa, as áreas verdes centrais dispõem de paisagismo planejado e com frequente manutenção. Ademais, tais espaços são constituídos de equipamentos urbanos que 
auxiliam na interação harmônica entre o cidadão da região com o meio ambiente - como quiosques, academias ao ar livre - proporcionando um bem-estar socioambiental aparente.

Quanto às praças de regiões periféricas, nota-se que a arborização não foi implantada de forma a estimular a qualificação socioambiental do espaço, gerando espaços de subutilização - seja pela ausência de sombreamento ou pela falta de padronização e locação. Como consequência, emergem-se carências socioambientais como sensações de desconforto ambiental e ausência de biodiversidade urbana, refletindo também em ações de redução do convívio coletivo e das áreas de lazer disponíveis.

Acerca de tais disposições, é curioso observar que embora arborizados, bairros centrais apresentam alta taxa de impermeabilização do solo, enquanto zonas periféricas possuem maiores índices de cobertura vegetal, contudo, não planejada. Nesse contexto, é necessário ressaltar a importância de se planejar adequadamente os sistemas arbóreos, pois, caso contrário, tais espécies podem incorrer em riscos à população adjacente, como a proliferação de vetores e doenças tropicais. Além disso, esta situação também pode resultar em incompatibilidades técnicas entre os meios natural e antropizado a partir do crescimento randômico de vegetação em áreas públicas (Figura 5) - dificultando a segurança pública, a operação de transporte coletivo, os comércios locais e as habitações dessas regiões.

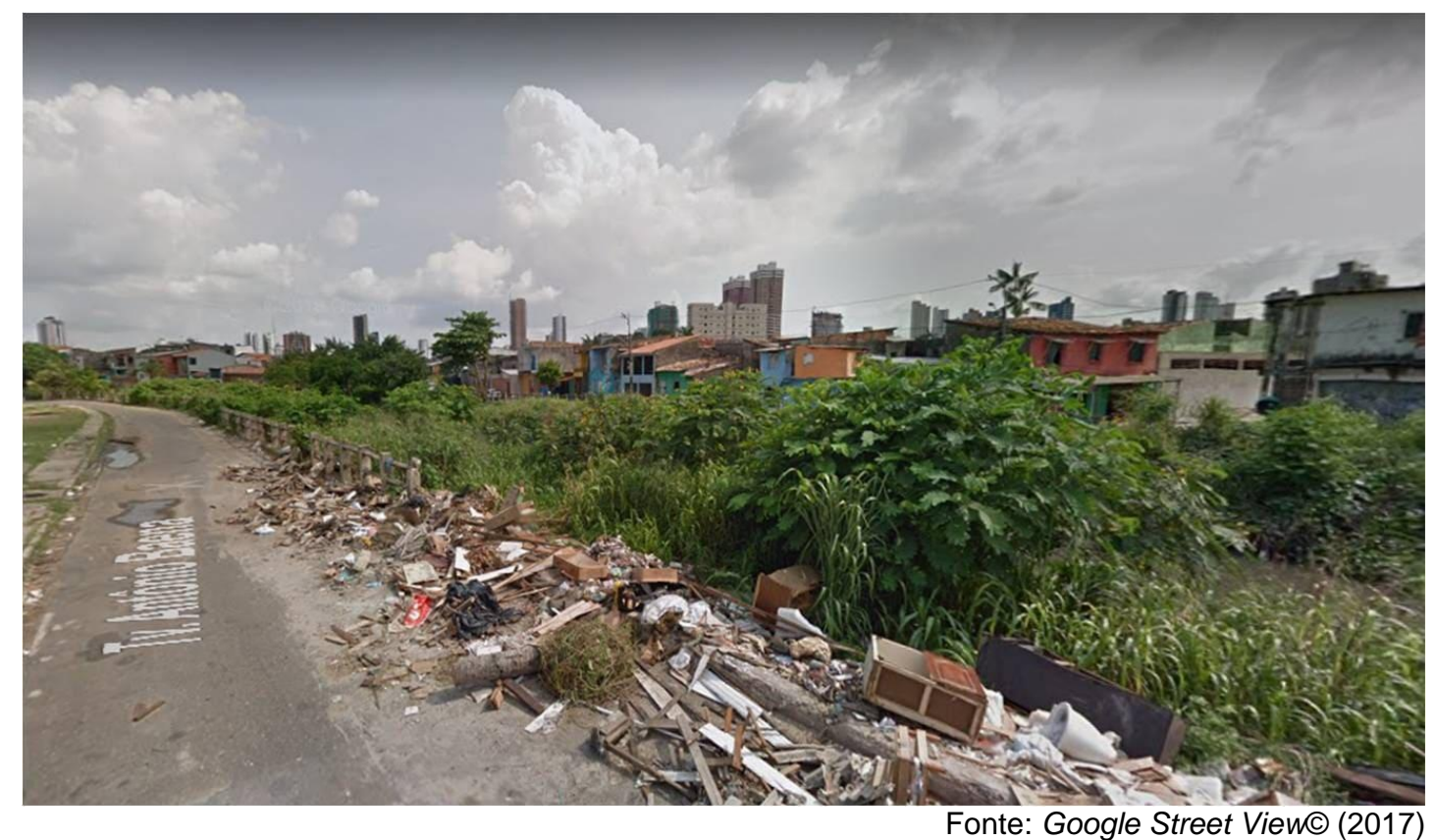

Figura 5. Rua Antônio Baena, no bairro da Pedreira: arborização não planejada como instrumento de proliferação de doenças urbanas e transtornos sociais.

Figure 5. Antônio Baena Street, in the district of Pedreira: unplanned afforestation as an instrument of proliferation of urban diseases and social disorders. 
Desse modo, verifica-se uma tendência de perpetuação da dicotomia socioambiental em Belém. Nesse prisma, áreas verdes de regiões valorizadas tendem a ser mais planejadas e possuírem mais manutenção do que aquelas cujo interesse imobiliário não é iminente. De forma análoga, regiões de potencial imobiliário tendem a sofrer intervenções com melhorias na infraestrutura urbana para consolidar tal atratividade mercadológica, incluindo a implantação de redes arbóreas que auxiliam na garantia de um bem-estar ambiental.

$\mathrm{Na}$ contramão disso, regiões de aglomeração subnormal e sem tendência de valorização imobiliária não apresentam intervenções socioambientais efetivas no território, confirmando a premissa de que o acesso à qualidade ambiental urbana é mais um privilégio do que um direito inerente à condição de morador da urbe. Assim, os espaços verdes se capitalizam implicitamente, tornando o direito à cidade arborizada uma utopia enquanto balizadora de políticas públicas socioambientais na cidade das mangueiras.

\section{CONCLUSÕES}

A organização do território belenense é marcada pelas contradições socioeconômicas que refletem diferentes manifestações físicas de meio ambiente urbano. Nesse contexto, foi ressaltado que aspectos socioambientais da cidade sempre estiveram associados à dimensão socioeconômica do espaço, de modo a gerar diferentes experimentações dos sistemas arbóreos e espaços verdes. Com isso, verificou-se que a noção de qualidade socioambiental urbana se estratifica segundo o binômio centro-periferia, com percepções distintas do que ser uma cidade das mangueiras significa na prática.

Dessa forma, pôde-se verificar que arborizar cidades é um ato que extrapola conceitos ambientais, impactando diretamente nos setores sociais, econômicos, políticos e culturais do meio urbano - resultando em fenômenos de diferenciação do território - como o privilégio verde. Ademais, observou-se que os atuais processos de constituição paisagística de centros urbanos é o principal impasse na efetivação do direito à cidade arborizada, uma vez que os mesmos são consoantes de interesses imobiliários, e não de políticas públicas voltadas aos grupos de vulnerabilidade e de dignificação socioambiental.

Como contribuição acadêmica, este estudo buscou explorar o campo ainda não difundido em âmbito nacional da capitalização da arborização urbana, de modo a fomentar futuras discussões acerca das consequências que tal fenômeno pode gerar na sociedade brasileira a médio e longo prazo. Como contribuição prática, a pesquisa almejou direcionar a percepção dos gestores de políticas públicas na promoção de medidas mais incisivas quanto à implantação e manutenção de áreas verdes urbanas, mitigando desigualdades socioambientais como prelúdio a possíveis reduções de disparidades socioeconômicas. 
Por fim, cabe questionar como Belém pode promover o slogan de "Cidade das mangueiras" sem que o mesmo divirja de uma realidade aquém dos padrões de arborização desejados? Como a cidade pode dialogar sobre bem-estar socioambiental quando a população não experimenta de forma homogênea condições suficientes de planejamento, desenvolvimento e conservação de seus sistemas arbóreos? Por fim, como promover o genuíno direito à cidade arborizada sob uma perspectiva socioespacial condicionada à dinâmica econômico-imobiliária? Talvez, o rompimento destes paradigmas seja o marco inicial da real requalificação ambiental que as cidades brasileiras, e especialmente a capital paraense, realmente necessitam para alcançar o direito à cidade arborizada.

\section{REFERÊNCIAS}

AIROZA, L. O. V. Cidade das Mangueiras: aclimatação da mangueira e arborização dos logradouros belenenses (1616-1911). Belém: Editora Amazônia, 2010.

BARROS, A. P. S.; AZEVEDO, A. C. J.; DIAS, E. R. S.; OLIVEIRA, H. M. P. Planejamento Urbano, áreas verdes e qualidade de vida: uma análise comparativa entre os bairros Terra Firme e Cidade Velha - Belém-PA. Revista Eletrônica Geoaraguaia, Araguaia, v. 7, n. 2, p. 69-85, 2017.

BORGES, C. A. R. F; MARIM, G. C.; RODRIGUES, J. E. C. Mapeamento da Cobertura Vegetal do bairro da Marambaia - Belém/PA. Revista da Sociedade Brasileira de Arborização Urbana, Piracicaba, v. 7, n. 4, p. 16-26, 2012.

BRASIL, H. M. S. Caracterização da arborização urbana: O caso de Belém. Belém, 1994. Tese (Doutorado em Ciências Biológicas) - Instituto de Ciências Biológicas, Universidade Federal do Pará, 1994.

CARDOSO, A. C. D.; LIMA, J. J. F.; VENTURA NETO, R. S.; RODRIGUES, R. M.; XIMENES, J. P.; GOMES, T. V. Forma urbana de Belém e seus desdobramentos para a formação de um sistema de espaços livres acessível à população. Revista Paisagem e Ambiente - Ensaios, São Paulo, n. 37, p. 11-34, 2016.

DEL FIORI, D.; BARBOSA FILHO, J.; SILVA, L. B.; NASCIMENTO, L. R. C. Valoração econômica dos ativos ambientais provenientes da arborização da cidade de Manaus-AM. Sinergia - Revista do Instituto de Ciências Econômicas, Administrativas e Contábeis (ICEAC), Manaus, v. 22, n. 2, p. 23-33, 2018.

FONTES, L. O. São Paulo nos anos 2000: segregação urbana e mobilidade social em termos de renda e escolaridade. Revista Brasileira de Estudos Urbanos e Regionais, São Paulo, v.20, n.2, p.304-324. 2018.

GAMA NETO, O. Arborização urbana em Belém: diálogo entre tempos. Dissertação (Mestrado em Arquitetura e Urbanismo) - Faculdade de Arquitetura e Urbanismo, Universidade federal do Pará, 2013. 
GUSMÃO, H. A. S.; SOARES, D. A. S. Processo desigual do espaço: o processo de verticalização em Belém (PA). Revista Contribuciones a las Ciencias Sociales, Cidade do México, jan./mar, 2018.

HARVEY, D. Cidades Rebeldes: Do direito à cidade à revolução urbana. São Paulo: Editora Martins Fontes, 2014.

INSTITUTO BRASILEIRO DE GEOGRAFIA E ESTATÍSTICA - IBGE. Características urbanísticas do entorno dos domicílios. 2012. Disponível em: <https://biblioteca.ibge.gov.br/ visualizacao/periodicos/96/cd_2010_entorno_domicilios.pdf> Acesso em 18 jan. 2019.

JUSTINO, S. T. P., MORAIS, Y. Y. G. A., DE ALMEIDA NASCIMENTO, A. K., SOUTO, P. C. Composição e Georreferenciamento da arborização urbana no distrito de Santa Gertrudes, em Patos-PB. Revista da Sociedade Brasileira de Arborização Urbana, Curitiba, v. 13, n. 3, p. 24-35, 2019.

LEFEBVRE, H. O Direito à cidade. São Paulo: Editora Moraes, 2001.

LIMA, J. J. F.; SANTOS, R. B.; SENA, L. F. A.; ARAÚJO, C. L. C. Estrutura Social e Organização Social da Região Metropolitana de Belém. In: CARDOSO, A. C. D.; LIMA, J. J. F. Belém: transformações na ordem urbana. Rio de Janeiro: Editora Letra Capital, Observatório das Metrópoles, p. 145-172. 2015.

MOREIRA, E. Belém e sua expressão geográfica. Belém: Imprensa Universitária, 1966.

OLIVEIRA, J. D.; BIONDI, D.; BATISTA, A. C.; REIS, A. R. N.; NESI, J. Atenuação do ruído do tráfego de vias urbanas pela vegetação em Curitiba - Paraná. Revista da Sociedade Brasileira de Arborização Urbana, Curitiba, v. 13, n. 2, p. 13-28. 2018.

RODRIGUES, J. E. C.; LUZ, L. M.; SARAIVA, J. S. Análise Morfológica dos bairros de Nazaré e Guamá no processo de redução das áreas verdes urbanas no município de Belém-PA. In: VI CONGRESSO IBEROAMERICANO DE ESTUDIOS TERRITORIALES Y AMBIENTALES, 2014, São Paulo.... Anais... São Paulo, p. 2813-2838. ISBN: 978-85-7506232-6. São Paulo, 2014.

SARGES, M. N. S. Memórias do velho intendente Antonio Lemos (1869-1973). Belém: Editora Paka-Tatu, 2004.

SILVA, D. A.; BATISTA, D. B.; BATISTA, A. C. Avaliação qualitativa da arborização com Mangifera indica nas ruas de Belém-PA. Revista Acta Biológica Catarinense, Joinville v. 1, n. 5, p. 34-45, 2018.

SILVA, D. A.; BATISTA, D. B.; MARTINI, A. Percepção dos moradores de Belém-PA sobre a arborização de ruas com Mangifera indica $L$. In: V CONGRESSO BRASILEIRO DE GESTÃO AMBIENTAL, 2014, Belo Horizonte. Anais... Belo Horizonte, 2014.

SOARES, A. A. S.; CARVALHO, A. C. Desafios da Governança do espaço urbano na Era do Antropoceno, e o caso das inundações e alagamentos em Belém-PA. Revista GeAmazônia, Belém, v. 6, n. 11, p. 105-142. 2018.

VENTURA NETO, R. S.; CARDOSO, A. C. D. A evolução urbana de Belém: trajetória de ambiguidades e conflitos socioambientais. Cadernos Metrópole, São Paulo, v. 15, n. 29, p. 5575, jan./jun., 2013. 
VIEIRA, D. C. M. R.; RODRIGUES, J. C.; RODRIGUES, J. C. Mapeamento e Análise das desigualdades socioespaciais: abordagem interpretativa a partir da cidade de Belém, Pará. Revista Geosaberes, Fortaleza, v. 9, n. 17, p. 1-21, 2018.

VIEZZER, J.; BIONDI, D.; BATISTA, A. C.; BRANDT, D. Perfil dos usuários e sua percepção dos elementos de composição paisagística das praças de Curitiba-PR. Revista da Sociedade Brasileira de Arborização Urbana, Piracicaba, v. 11, n. 3, p. 01-16, 2016.

WANDERLEY, R. J. C.; PEREZ, C. A. M.; RABELO, D.; SOUZA, P. A.; GIONGO, M.; SANTOS, A. F. Estudo Quali-quantitativo e percepção ambiental da arborização do setor Jardim Sevilha Gurupi-TO. Revista d Sociedade Brasileira de Arborização Urbana, Piracicaba, v. 12, n. 4, p. 53-68, 2017. 